Psychology of Language and Communication 2021, Vol. 25, No. 1

Sciendo

DOI: $10.2478 /$ plc-2021-0009

\author{
Cristina Vereda-Alonso ${ }^{1}$ and Mercedes Gonzalez-Sanchez ${ }^{2}$ \\ ${ }^{1}$ Filología Inglesa, Francesa y Alemana, University of Malaga, Spain \\ ${ }^{2}$ Personalidad, Evaluación y Tratamiento Psicológico, University of Malaga, Spain
}

\title{
Motor-type aphasia in English and Spanish and its relation to the linguistic variables intervening in reading
}

\begin{abstract}
This pilot study was designed to explore the way linguistic variables affect reading in English and Spanish in the context of motor-type aphasia. The participants were two speakers with English L1, two English-Spanish bilinguals, and four speakers with Spanish L1. The Boston Diagnostic Aphasia Examination (BDAE) and Psycholinguistic Assessments of Language Processing in Aphasia (PALPA) were used to assess the participants' reading skills. L1 English, Spanish, and bilingual participants used both the lexical and sublexical route when reading, but utilized one route more than the other depending on their linguistic profile. L1 Spanish participants used the damaged phonological route, producing many neologisms or non-answers. L1 English participants, utilizing the lexical route, produced more lexicalizations than neologisms. The bilingual participants showed interlanguage interference by producing many spelling-sound regularizations. These results suggest that orthographic depth and different linguistic variables affect individuals with motor-type aphasia depending on the language they speak.
\end{abstract}

Key words: motor-type aphasia; reading skills; acquired dyslexia; linguistic effects; bilingualism

Address for correspondence: Cristina Vereda-Alonso, Filología Inglesa, Francesa y Alemana, University of Malaga, Calle Jamaica 25, 29010, Málaga, Spain

E-mail: crisveredalonso@uma.es

This is an open access article licensed under the CC BY NC ND 4.0 License. 
Individuals with motor-type aphasia, because of brain injury, may present a deficit in the reading process called acquired dyslexia. There are three main types of dyslexia: superficial, phonological, and deep. These are called central dyslexias as the lexical processing mechanisms are affected. There are other types that present deficits in the identification of linguistic signs: attentional, visual, negligent, and pure dyslexia (Cuetos, 2013; McCarthy \& Warrington, 1990).

Central dyslexia or alexia is a reading impairment affecting production and/or comprehension. Although reading is an independent cognitive activity (Cuetos, 2006, 2013), the processes involved also require the production and comprehension of language. Therefore, aphasic individuals, especially those with nonfluent aphasia, also present with reading disruption.

Dyslexia is relevant in this pilot study, as it is an aphasia co-morbidity, and our participants suffered from motor-type aphasia - also known as Broca's aphasia - affecting oral production and, therefore, also oral reading. This disruption does not only affect oral reading but also the processes involved in reading (Cuetos, 2013). These processes involve using a double route to read: a lexical route for whole-word reading and a sublexical/phonological route for letter-by-letter reading (Cuetos, 2013; Dickens et al., 2019).

Our pilot study aimed to investigate whether orthographic depth affects word reading, and different linguistic variables intervene in the process depending on whether the individual with motor-type aphasia speaks English, Spanish, or both languages.

\section{Dual-Route Model of Oral Reading}

The double route, designed by Coltheart $(1978,2005)$, explains the process taking place from the moment of seeing a written word to the phonological output (speech).

According to this model, readers have two ways to proceed when reading a word. If the word is stored in the mental lexicon, the reader uses the lexical route. If the word is not registered in the mental lexicon, the reader uses the phonological route (see Figure 1).

Based on Lesser and Milroy (1993), if given the word "dog," readers would first analyze the features and letter units of the word. If a match is found in the mental lexicon, an orthographic input is generated.

Once the orthographic form of the word is shaped, there are two ways to proceed: one accessing the semantic system and the other one, known as the direct route, reaching the phonological output from the orthographic input bypassing the semantic system.

The first route has orthographic-semantic-phonological processing. The orthographic form of the word accesses the semantic system, where it will look for a word that matches the definition of "a four-legged domestic animal." If there were damage in the way in or out of the semantic system, the word "cat" 


\section{Dual Route Model}

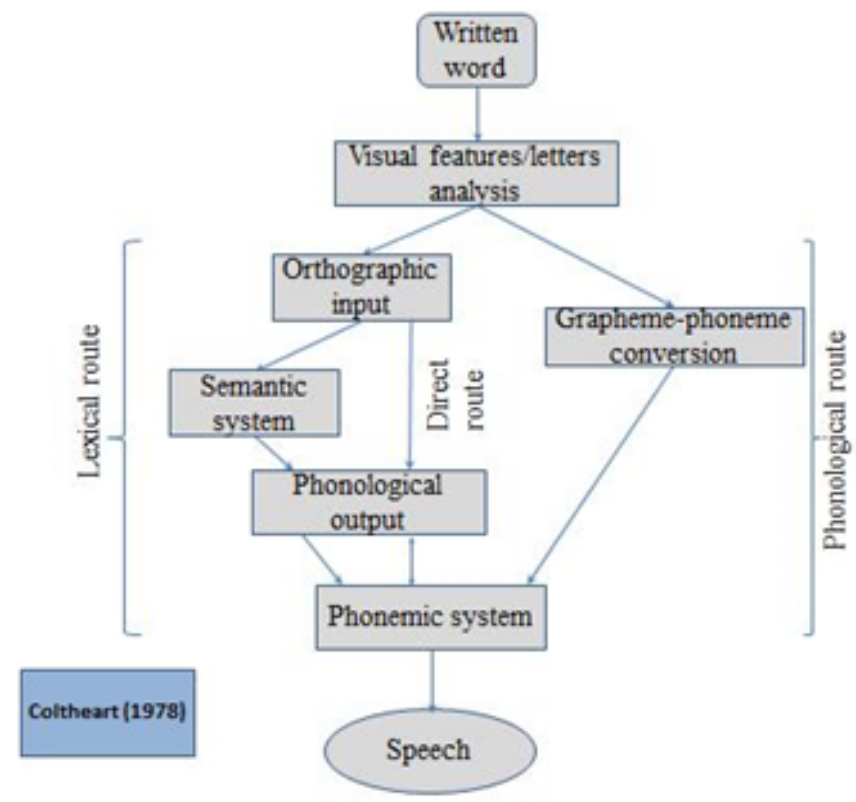

Figure 1. Dual-route model based on Coltheart's (1978).

may be retrieved (Lesser \& Milroy, 1993). In this case, the reader would produce a semantic paralexia (a semantic error).

Once the definition is retrieved, the orthographic input (d-o-g) will try to match its correspondent phonological output. When damage occurs in the phonological output, the phonological reading from the other route takes over and produces a regularized pronunciation of the word. If, for example, the word to pronounce were "quay," it would be regularized as /kwei/. When this process in the lexical route is damaged, surface dyslexia occurs. The term was first introduced by Marshall and Newcombe (1973).

Within the first route, there is an alternate subroute called the direct route. Denise et al., Randi, and Markus (2002) also referred to this subroute as a possible third route for reading. The direct route is used when the reader recognizes a written word but does not remember or know the meaning. In this case, the orthographic input is directly translated into its phonological output, bypassing the semantic system.

The second route, called the phonological route, is used when the reader is faced with an unknown or invented words (neologisms). These are also called pseudowords when they are visually similar to or are pronounced as a real word (e.g., "ked" confused with "kid" or "brane" confused with "brain"). 
In case of damage, the reader would have trouble reading long words, as, by using this route, words are read letter by letter from left to right. They would also have trouble reading nonwords and pseudowords, which would be either lexicalized (read as a real word) or not read at all. Words with low imageability and frequency, which highly depend on phonological reading, would be misread as neologisms or confused with a visually similar word, for example, "hut" and "hat." This is called visual/phonological paralexia. It usually happens when the target word has a low semantic charge. Words with affixes will also be read with omissions, as the reader with damage to the phonological route tends to read only the lemma. For example, "duck" instead of "ducks," "camp" instead of "camper," or "bleed" instead of "bled." When this route is damaged, phonological dyslexia occurs.

It is argued that both routes work simultaneously. Coltheart et. al. (2001) stated that if the lexical route receives feedback from the phonological route via their shared phonemic system, there is interference in the speech. This explains why damage to one route or the other affects reading. One route needs the other. When both routes are damaged, deep dyslexia happens. Marshall and Newcombe (1973) were the first to describe it.

When deep dyslexia occurs, the problems the reader must face are the same ones found in case of phonological dyslexia. The only difference is the production of semantic paralexias, that is, damage to the access to or from the semantic system, like reading "road" instead of "car" (Lesser \& Milroy, 1993). Therefore, it is argued that both phonological and deep dyslexia are two points on the same continuum (Friedman, 1996). Davies et al. (2010) also showed that a patient suffering from deep dyslexia presented with only phonological dyslexia after rehabilitation, as he stopped producing semantic errors.

\section{Ortographic Depth}

Orthographic depth is key to understanding the difference between opaque languages such as English and French and transparent languages such as Spanish and Italian. Sánchez-Benedito (2003) stated that English pronunciation does not follow fixed rules. This fact is the reason why a high number of words in English have an exceptional pronunciation (e.g., [steak] $\rightarrow$ /ste1k/ instead of / st $1 \mathrm{k} /$ ). On the other hand, transparent languages such as Spanish do follow fixed pronunciation rules and have a high grapheme-phoneme mapping consistency.

Davies and Cuetos (2010) questioned whether orthographic depth affected reading at a cross-linguistic level, as Ardila (1998) had previously stated that writing and reading systems of opaque and transparent languages are different. The fact that a language is considered to have a transparent grapheme-phoneme correspondence does not mean that its orthography is entirely transparent. According to Bravo-Valdivieso and Escobar (2014), this lack of full transparency occurs in Spanish, as its "orthographic expressions include components from 
Arab such as the letter $\mathrm{j}$ and letters that impede learning such as $\mathrm{w}, \mathrm{h}$ and 11 , or those that have two pronunciations such as g and y" (p. 443). Another example is the consonant $r$. When $r$ is placed at the beginning of a word, its phoneme is $/ \check{r} /$, as in [ratio] / ‘ra tjo/. However, when it is in a middle position and between vowels its phoneme changes to /r/, as in [cara] /'ka ra/. However, even though Spanish readers depend on phonological reading more than English ones, it seems more likely that reading in Spanish relies on both lexical knowledge and graphemicphonemic mappings. Furthermore, the necessity to access meaning quickly implies lexical reading happens regardless of orthographic depth, as reading words phonologically is a slow process (Davies \& Cuetos, 2010).

Considering that the two routes are used in both transparent and opaque orthographies, it is suggested that some of the linguistic variables affect them in a different way. Nevertheless, Davies and Cuetos (2010) explained that it is hard to establish the rate at which the different linguistic variables affect transparent and opaque orthographies, as even within the same language, there may be variations in the way they influence reading processing.

\section{Linguistic variables}

The linguistic variables or effects are a series of specific phenomena that shape reading processing (see Figure 2). The following list shows the main elements that every reading model should include according to Lupker (2005), Cuetos (2006), and Kay et al. (2012):

- Word length effect: A word is more easily read when it contains fewer letters, especially when it is unfamiliar to the reader. Two hypotheses can be found in the literature. One states that all letters need to be identified before reading a word, the other claims that word recognition is global (Cuetos, 2006). According to Cuetos (2013), it is necessary to identify at least some of the letters even when the word is familiar to the reader

- Imageability effect: A word is easier to read when its semantic weight is high because it is easily visualized. The grammatical class also plays an important role. Nouns and adjectives with a higher semantic weight are easier to read than verbs and function words whose semantic weight is lower. Therefore, concrete nouns are easier to visualize than abstract nouns. Cuetos (2013) explained that individuals suffering from phonological dyslexia have trouble reading affixes. The reason underlying this phenomenon is that affixes are functional particles, that is, without semantic weight. Therefore, such patients will only read the stem of the word. So, morphology is also an important variable.

- Frequency effect: A word is easier to read when its frequency is higher. Vellutino (1982) observed that readers have lexical memory that allows them to identify words faster. This velocity would only slow down if 
the readers encountered new or low-frequency words. According to Morton (1979), this occurs because the threshold is lower when a word is repeated several times. Therefore, it will need less activation to be retrieved. Davies and Cuetos (2010) argued that frequency is often confused with age of acquisition, meaning that words that are acquired earlier are easier to retrieve from the mental lexicon. This fact increases speed and accuracy when the reader encounters one of these words. This confusion happens because words acquired earlier in life are also high frequency words.

- Spelling-sound regularity effect: Words with an exceptional pronunciation are regularized when they are unknown to the reader or there is damage to the lexical route, for example, pronouncing the word "recipe" /'resipi/ as /ri'saip/. The latter would have been the expected pronunciation of the word, whose origin is Latin, and which had been adapted to English pronunciation. As it is impossible to guess the etymology of a word unless the reader is an expert linguist, the only way to learn to read these exception words is by means of repetition. Therefore, frequency plays an important role in this process. The Spanish language does not contain exception words. However, with the increasing acquisition of Anglicisms and borrowings from other languages such as German or French, if these are not adapted to the Spanish writing system, they may be mispronounced, especially when the reader is unfamiliar with them. Iribarren (2007) suggested providing the readers with a set of words without their corresponding written accents. Readers suffering from surface dyslexia tend to mispronounce words when their written accents are removed. For example, if the reader is unfamiliar with the word "crater," they may read it as /kra 'ter/ instead of /'kra ter/, which would be the correct pronunciation.

- Nonwords and pseudowords effect: Coltheart et al. (2001) explained that reading models should be able to explain the following phenomena:

- pseudohomophones are read faster than nonwords;

- pseudohomophones based on high frequency words are read faster than those based on low frequency words;

- the bigger the N-size, the faster a nonword will be read.

The length effect also plays an important role in reading nonwords and pseudowords. Drawing on the explanation provided by Davies and Cuetos (2010), reading both nonwords and pseudowords relies on the phonological route. Therefore, the more letters a nonword or pseudoword has, the more effort the reader must make. 


\section{Dual route model and linguistic variables}

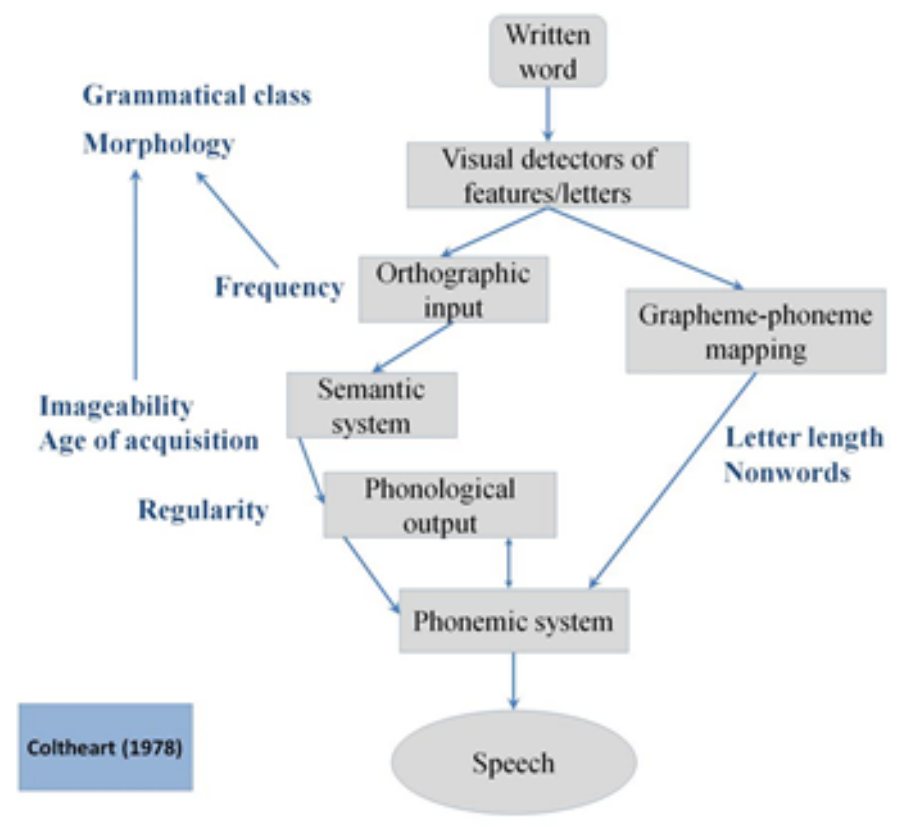

Figure 2. Dual-route model and linguistic variables.

\section{Bilingualism}

The differences between the English and Spanish languages are clear: Their phonemic systems are different, the relationship between orthography and pronunciation is consistent in Spanish but arbitrary in English, and Spanish children learn to read faster than English children (Davies \& Cuetos, 2010). These findings were corroborated by Ijalba and Obler (2015), who conducted an experiment with of monolingual English and Spanish speakers. Both groups had to learn to read a fabricated language that included both transparent and opaque words. The results showed that the Spanish participants were faster learners when they had to read transparent words but found opaque words more difficult. The English participants were slower but more successful at reading opaque words than transparent words. However, it is also important to know what happens when both English and Spanish languages are present in the brain, especially considering the differences in orthographic depth.

Some authors have attempted to define the wide spectrum of bilingualism (Hamers \& Blanc, 1983; Valian, 2015). Although there are some studies on second language acquisition and teaching with children, according to the literature review made by Or-Kan et al. (2020), there has been a lack of substantial research 
on bilingualism and its various aspects over the last five years.

Despite the lack of substantial research on bilingualism, there is an aspect that is continuously addressed in the literature: the critical period hypothesis. According to Lenneberg (1967), who formed this hypothesis, a person can only become native-like in a second language when their L2 is acquired before puberty. The reason is that cognitive maturity is achieved at this stage, around 11 years old. Edmonds and Kiran (2004) argued that depending on the level of proficiency in each language, bilinguals could be divided into L1-L2 balanced and L1 dominant. L1-L2 balanced bilinguals acquired both languages at the same time, whereas L1 dominant bilinguals acquired or learned the L2 once the L1 was already established.

Information on when the bilingual individuals with dyslexia-type manifestations acquired their L2 is relevant to know if they are L1-L2 balanced or L1-dominant. Unfortunately, most leading views on dyslexia and bilingualism focus on children and developmental dyslexia, instead of bilingual adults with acquired dyslexia. However, some interesting research has analyzed the overlap between L1 and L2 in bilingual adults with aphasia (Hosogi \& de Mattos, 2012; Miozzo et al., 2010; Tainturier et al., 2011).

\section{Previous Works}

Th In previous studies, another linguistic variable was detected in bilinguals with aphasia: the double transfer effect. Some authors analyzed this effect on reading (Hosogi \& de Mattos, 2012; Miozzo, et al., 2010; Tainturier et al., 2011), and found that the same types of errors were observed in both L1 and L2, disregarding orthographic depth and proficiency in each language. This supports Edmonds and Kiran's (2004) hypothesis that aphasia, irrespective of its type, affects both languages equally.

Transfer is a common linguistic variable that can be observed in children learning a second language whose L1 (first language) is already completely established in their mental lexicon. This phenomenon was analyzed by Vereda (2018), who observed that several errors were transfers from L1 (Spanish) to L2 (English). However, in bilinguals with acquired aphasia who speak a deep/opaque and a shallow/transparent language, this transfer takes place in both directions: from L1 to L2 and from L2 to L1. This conclusion was reached by Lallier and Carreiras (2018) after verifying that a cross-linguistic blending occurs between the transparent and opaque orthographies.

It is worth mentioning that here are more studies on assessment and rehabilitation of monolingual speakers with motor-type aphasia (Cuetos, 2013; Bravo-Valdivieso \& Escobar, 2014; Ijalba \& Obler, 2015). These studies found that individuals with motor-type aphasia speaking a transparent language have more ease at reading words with direct grapheme-phoneme mapping, whereas 
those speaking an opaque language performed better with exception words.

Because of what is reflected in most studies, Ardila (1998) claimed that phonological and deep dyslexia would only affect monolingual Spanish speakers under certain circumstances, such as speaking another language, having high education, suffering from motor-type aphasia, and exposition to a long-period rehabilitation. However, other authors who treated monolingual Spanish speakers with motor-type aphasia found that their patients presented either deep or phonological dyslexia (Cuetos et al., 1996; Davies et al., 2010; Davies \& Cuetos, 2010). This meant that their participants used the lexical route to read, although it was not clear if they (the participants) met the conditions exposed by Ardila (1998).

The present pilot study focused on reading processing in English and Spanish speakers with motor-type aphasia. It aimed to investigate the possible differences in the way the three groups (monolingual English, bilingual English-Spanish, and monolingual Spanish participants) process reading.

It was hypothesized that orthographic depth could influence the way linguistic variables affect reading in individuals with acquired motor-type aphasia who speak English, Spanish, or both. Considering this hypothesis, we expected to obtain results that reflect this difference in the three groups made of two bilinguals who speak Spanish and English, two monolingual English speakers, and four monolingual Spanish speakers.

The research questions of this study are as follows:

1. Will orthographic depth affect word reading in individuals with motortype aphasia?

2. Will the same linguistic variables affect Spanish, English, and bilingual speakers with motor-type aphasia?

\section{Methodology}

\section{Participants}

Eight participants with motor-type aphasia; two English, two English-Spanish bilingual, and four Spanish speakers, were recruited for this study. They took a series of linguistic tests to assess their performance at language production, auditory comprehension, repetition, naming, reading, and writing, with a special focus on reading. The selection of participants took place in four different phases:

Phase 1. Contacting social centers with an agreement to treat individuals with aphasia, clinics in Malaga and its coastal cities, where most English expatriates live, and the association of people with aphasia in Malaga called AFAMA (Asociación de Afásicos de Málaga).

Phase 2. Interviewing candidates to verify their suitability for the study.

Phase 3. Nineteen participants were selected, but 11 of them were discarded, 
as they scored less than $<25 \%$ in the lexical-morphological reading test from PALPA 34 and EPLA 32 or abandoned the study. The selected eight participants took the Raven's Progressive Matrices (Raven et al., 1996) and Rey's Complex Figure (Rey \& Osterrieth, 1994) tests to ensure their cognitive level and visual memory were normal.

Phase 4. An evaluation program was created. Timetables were elaborated to suit each patient's needs.

\section{Participants' Profiles}

\section{Bilingual group}

Participant 1. CU was a 36-year-old female who had a stroke. Her first language was Spanish and she started to learn English in school. She became proficient in English while living and studying in English-speaking countries. She loved reading before the stroke. She received speech therapy rehabilitation in English for four months and was trained to use her left hand due to right-hand hemiplegia.

Participant 2. RB (1968-2016) was a 47-year-old male. English was his native language. He was also native-like in Spanish as he had moved from England to Spain when he was 11 years old. He suffered cerebral edema that affected his right hemisphere and triggered motor-type aphasia. This provoked disruptive language production and left-hand hemiplegia. He received speech therapy rehabilitation in both English and Spanish. RB did not receive a university education. He did not like reading.

\section{English group}

Participant 3. AG, a 42-year-old male, suffered a stroke in the left hemisphere during a surgical procedure that was performed nine years ago to fix a mitral valve prolapse before participating in the study. This caused him right-hand and leg hemiplegia, and disruption of language production. He was hospitalized for two months and received rehabilitation for another two months. Discharged from the hospital, AG continued physical and speech therapy rehabilitation at home. He tried traditional speech-therapy rehabilitation (based on articulating isolated sounds to gradually start working on syllables, words, phrases, sentences, reading, and conversation) as well as alternative therapies including acupuncture, massages, tai chi, yoga, restriction-induced movement therapy, water therapy, videogames, and speech-therapy special software. AG had university education. He loved reading before acquiring motor-type aphasia.

Participant 4. JMW, a 75-year-old female, suffered from a left-hemisphere cerebral hematoma in the cortical temporo-parietal region five years prior to participating in the study. Progressive speech disruption began to appear in August 2015 accompanied by left-facial paralysis and motor impairment in the legs owing to an ictus acquired two years before. Besides the articulation 
problem, the patient has transcortical-motor aphasia causing naming problems. Her reading and writing abilities are well preserved. Due to dysarthric language, her speech was hard to understand. However, she could clearly articulate words when she adopted a slower pace of speaking. She loved reading before the lesion.

\section{Spanish group}

Participant 5. GP, a 55-year-old female, had a stroke 23 years ago. She lost her ability to produce speech and has right-handed hemiplegia. Nowadays, after rehabilitation with her speech therapist, she can engage in a conversation without significant limitations. She finished elementary education at the age of 14. GP liked reading novels before the stroke, but she does not do it anymore.

Participant 6. JAP, a 61-year-old male, had cerebral bleeding 17 years before participating in the study. His right hand and leg became paralyzed. He was operated on and stayed in the hospital for two months without producing or understanding speech. After rehabilitation with a speech therapist, he can communicate and engage in conversations but he still has some difficulty producing language due to apraxia of speech. JAP only has elementary education. He disliked reading before the CVA (cerebrovascular accident or stroke happens when blood flow does not reach the brain). Now, he still likes telling jokes and socializing.

Participant 7. PM, a 67-year-old male, had an ischemic (an ischemic CVA occurs when the source of the stroke is a blood clot blocking an artery to the brain) cerebrovascular accident. He did not know when this happened because he had already had motor-type aphasia by the time his family admitted him to a nursing home in 2007. He did not receive any speech rehabilitation therapy. PM can communicate mainly using gestures and onomatopoeias. His speech production is ungrammatical and limited to lexical words. He finished elementary education at the age of 13 . He did not like reading prior to aphasia.

Participant 8. JCM,a 40-year-old male, had cerebral bleeding 14 years prior to participation in the study. Since then, he has been receiving speech therapy rehabilitation for motor-type aphasia. He has mild right-hand hemiplegia but can manage to write using his left hand. His treatment includes a tablet that improves his performance. Currently, his aphasia is mild; he can engage in conversations without major difficulties. JCM completed his studies at university before his cerebrovascular accident. He loved reading before acquiring aphasia.

\section{Instruments}

Each participant was assessed in five one-hour sessions that took place on different days according to their availability.

First, each participant was assessed using the short version of the Boston Diagnostic Aphasia Examination (Goodglass \& Kaplan, 2001) for their respective linguistic profiles and severity rates.

Second, each participant took a series of visual lexical decision and reading tests: the EPLA battery (Lesser et al., 1995) for the Spanish group and the PALPA 
battery (Kay et al., 2012) for the bilingual and English groups. Initially, the two bilingual participants (CU and RB) were intended to complete both tests. However, RB died shortly after taking the PALPA tests.

The PALPA battery (Kay et al., 2012), translated into different languages, controls all the basic variables affecting the process of reading, including letter length, syllable length, imageability and frequency, grammatical class, morphology, spelling-sound regularity, and nonword reading.

\section{Results}

Mann Whitney-Wilcoxon test showed no statistical differences between the three groups. The variables compared here were the following: letter length, imageability and frequency, grammatical class, morphological ending, spellingsound regularity and nonword reading.

Since there are many tables, one per test taken, only two of them will be shown, as no statistical differences were found between the groups due to the small sample size.

The participants were paired according to their results obtained in the Boston Diagnostic Aphasia Examination test. The English monolinguals and the EnglishSpanish bilinguals took the test in English, whereas the Spanish monolinguals took the Spanish version.

Once the linguistic profiles were compiled, the participants were matched in lexical reading, sentence reading, and severity rate, so their performances were as similar as possible (see Table 3 ).

The results each pair obtained on the PALPA/EPLA tests were compared to see if there were any significant differences. For this purpose, the Fischer's exact test was used.

The Fischer's exact test showed significant differences in the imageability and frequency tests, both in the visual-lexical decision (see Table 4) and reading (see Table 5). The Spanish participants GP and JAP had more difficulty reading low-imageability words.

\begin{tabular}{|l|c|c|}
\hline \multicolumn{3}{|l|}{ Table 1. Mann-Whitney-Wilcoxon calculation for spelling-sound regularity reading. } \\
\hline Reading: Spelling-sound regularity & $W$ & $p$ \\
\hline Regular & 4.5 & .380 \\
\hline Exception & 7.5 & 1.0 \\
\hline
\end{tabular}

\begin{tabular}{|l|c|c|}
\hline Table 2. Mann-Whitney-Wilcoxon calculation for nonword reading. & \multicolumn{2}{l|}{} \\
\hline Reading: Nonwords & $W$ & .457 \\
\hline 3 letters & 5.0 & .378 \\
\hline 4 letters & 4.5 & .357 \\
\hline 5 letters & 4.5 & .539 \\
\hline 6 letters & 5.0 & .439 \\
\hline
\end{tabular}




\begin{tabular}{|c|c|c|c|}
\hline Pair & Word reading & $\begin{array}{c}\text { Sentence } \\
\text { reading }\end{array}$ & Severity rate \\
\hline CU (bilingual) & $100 \%(15 / 15)$ & $40 \%(2 / 5)$ & 4 \\
\hline GP (Spanish) & $80 \%(12 / 15)$ & $40 \%(2 / 5)$ & 4 \\
\hline AG (English) & $80 \%(12 / 15)$ & $60 \%(3 / 5)$ & 4 \\
\hline JAP (bilingual) & $60 \%(09 / 15)$ & $0 \%(0 / 5)$ & 3 \\
\hline RB (bilingual) & $13 \%(2 / 15)$ & $20 \%(1 / 5)$ & 3 \\
\hline \begin{tabular}{|l} 
PM (Spanish) \\
\end{tabular} & $53 \%(8 / 15)$ & $0 \%(0 / 5)$ & 1 \\
\hline JMW (English) & $100 \%(15 / 15)$ & $80 \% \quad(4 / 5)$ & $1 *$ \\
\hline JCM (Spanish) & $100 \%(15 / 15)$ & $100 \%(5 / 5)$ & 4 \\
\hline
\end{tabular}

\begin{tabular}{|l|c|c|c|}
\hline \multirow{2}{*}{ Table 4. Scores in visual lexical decision: imageability and frequency. } \\
\hline \multirow{2}{*}{ Variables } & \multicolumn{2}{c|}{ Participants } & \multirow{2}{*}{$p$} \\
\cline { 2 - 3 } & CU (bilingual) & GP (Spanish) & \\
\hline HI HF & 20 & 18 & .487 \\
\hline HI LF & 18 & 18 & 1 \\
\hline LI HF & 20 & 5 & .001 \\
\hline LI LF & 15 & 2 & .001 \\
\hline Nonwords & 75 & 63 & .010 \\
\hline
\end{tabular}

Note: $\mathrm{HI}=$ high imageability; $\mathrm{HF}$ = high frequency; LI = low imageability; LF = low frequency.

\begin{tabular}{|c|c|c|c|}
\hline \multirow{2}{*}{ Variables } & \multicolumn{2}{|c|}{ Participants } & \multirow[b]{2}{*}{$p$} \\
\hline & AG (English) & JP (Spanish) & \\
\hline HI HF & 18 & 16 & .661 \\
\hline HI LF & 18 & 11 & .031 \\
\hline LI HF & 17 & 9 & .019 \\
\hline LI LF & 18 & 7 & .008 \\
\hline
\end{tabular}

Note: $\mathrm{HI}$ = high imageability; $\mathrm{HF}$ = high frequency; LI = low imageability; LF = low frequency.

\section{Imageability and Frequency lexical reading (PALPA 31/EPLA 29)}

A significant difference was also found on the other reading tests scores, but they were not considered relevant for this study. However, there were important differences at a qualitative level in the reading tests for the variables Grammatical Class, Morphological Endings (see Table 6), Spelling-Sound Regularity (see Table 7), and Nonwords.

\section{Grammatical Class lexical reading (PALPA 32/EPLA 30)}

No significant difference was found except for verbs between the participants AG (English) and JAP (Spanish) $(\mathrm{p}=.004)$. In general, the Spanish participants 


\begin{tabular}{|c|c|c|c|}
\hline \multirow{2}{*}{ Variables } & \multicolumn{2}{|c|}{ Participants } & \multirow[b]{2}{*}{$p$} \\
\hline & RB (Bilingual) & PM (Spanish) & \\
\hline Regular & 5 & 8 & .462 \\
\hline Control Regular & 4 & 9 & .139 \\
\hline Derivational & 2 & 10 & .008 \\
\hline Control Derived & 4 & 13 & .002 \\
\hline Irregular & 3 & 9 & .060 \\
\hline Control Irregular & 8 & 9 & 1 \\
\hline
\end{tabular}

Note: Control variables are unaffixed words that looked like affixed words.

\begin{tabular}{|c|c|c|c|}
\hline \multirow{2}{*}{ Variables } & \multicolumn{2}{|c|}{ Participants } & \multirow[b]{2}{*}{$p$} \\
\hline & AG (English) & JAP (Spanish) & \\
\hline Regular words & 30 & 20 & .008 \\
\hline Exception words & 26 & 12 & .004 \\
\hline
\end{tabular}

produced more errors than the English monolingual and bilingual participants. However, the Spanish participants GP and PM performed better than the bilingual ones (CU and $\mathrm{RB})$ in adjective reading.

\section{Morphological-Endings lexical reading (PALPA 34/EPLA 32)}

A significant difference was found between the participants AG (English) and JAP (Spanish) for nonaffixed control irregular words reading. There was another significant difference between RB (bilingual) and PM (Spanish) on both derived and nonaffixed control derived word reading.

With the exception of AG (English), both the bilingual and monolingual English participants obtained lower results for regularly inflected word reading than their Spanish counterparts.

\section{Spelling-Sound Regularity lexical reading (PALPA 35/EPLA 33)}

A significant difference was found only for the pair of AG (English) and JAP (Spanish). However, the scores of the bilingual participants CU and RB for exception word reading were equal or lower than their Spanish counterparts. Their scores were the lowest.

\section{Nonword reading (PALPA 36/EPLA 34)}

No significant difference was found in nonword reading. However, the scores obtained by the Spanish participants were lower than their English and bilingual counterparts. The Spanish participants JAP and PM did not succeed in reading 
all three, four, five, six-letter nonwords. The numbers refer to the letter-length of the nonwords.

\section{Distribution of errors}

The errors made by the participants were divided into different types: nonresponses; phonological paralexias; semantic paralexias, derived paralexias; lexicalizations, regularizations, neologisms, omissions, and mixed paralexias ( see Table 8)

The two bilingual participants, $\mathrm{CU}$ and $\mathrm{RB}$ regularized more exception words than the other participants. In contrast, the Spanish participants produced more neologisms than the English and bilingual participants, except for the Spanish participant RB.

The Spanish participant JAP, who only had elementary education, was not a regular reader before the stroke and did not know other languages, produced 22 semantic paralexias.

\section{Discussion}

This study tested whether individuals with motor-type aphasia varied in the use of the dual route if their L1 was a transparent/shallow or opaque/deep language. We hypothesized that differences in orthographic depth would make some linguistic variables affect the participants more than others.

\section{Results analysis}

The Mann-Whitney-Wilcoxon test showed no difference between the three groups. This may be due to the small sample. However, when comparing the matched pairs with Fischer's exact test, some significant results were obtained. Both in the visual lexical decision (PALPA/EPLA 25) and oral reading (PALPA

\begin{tabular}{|l|c|c|c|c|c|c|c|c|c|}
\hline \multicolumn{1}{|l|}{ Table 8. Distribution of errors. } \\
\hline \multicolumn{1}{|c|}{ Participants } & NR & PP & SP & DP & Lex. & Reg. & Neolog. & Omiss. & MP \\
\hline CU (bilingual) & 0 & 8 & 0 & 0 & 5 & 19 & 12 & 11 & 0 \\
\hline GP (Spanish) & 4 & 38 & 3 & 3 & 9 & 2 & 57 & 5 & 4 \\
\hline AG (English) & 0 & 11 & 1 & 11 & 13 & 7 & 6 & 5 & 0 \\
\hline JAP (Spanish) & 68 & 18 & 22 & 0 & 0 & 1 & 40 & 0 & 1 \\
\hline RB (bilingual) & 45 & 50 & 0 & 7 & 13 & 13 & 37 & 13 & 2 \\
\hline PM (Spanish) & 134 & 22 & 5 & 3 & 0 & 1 & 30 & 4 & 2 \\
\hline JMW (English) & 0 & 2 & 1 & 2 & 1 & 6 & 2 & 11 & 0 \\
\hline JCM (Spanish) & 1 & 7 & 0 & 2 & 1 & 3 & 18 & 12 & 0 \\
\hline
\end{tabular}

Note. $\mathrm{NR}=$ nonresponses; $\mathrm{PP}=$ phonological paralexias; $\mathrm{SP}=$ semantic paralexias; $\mathrm{DP}=$ derived paralexias; Lex. = lexicalizations; Reg. = regularizations; Neolog. = neologisms; Omiss. $=$ omissions; $\mathrm{MP}=$ mixed paralexias. 
31/EPLA 29) tasks, significant differences were found between the pairs of CU (bilingual) and GP (Spanish), and AG (English) and JAP (Spanish) for low imageability words. Nevertheless, this result was not considered to be relevant as semantics affects patients irrespective of their language's orthographic depth (Cuetos, 2013).

Significant differences were also found between the pair of AG (English) and JAP (Spanish) for exception words in the Oral Reading: Spelling-Sound Regularity test (PALPA 35/EPLA 33). It is common that English speakers with phonological dyslexia produce more regularizations when reading exception words (Beeson et al., 2011).

Exception words are those whose grapheme-phoneme mapping is not direct. It had already been discussed in the theoretical part of the introduction that Spanish speakers with motor-aphasia usually have more difficulty at reading exception words as Spanish is considered a highly transparent language (Cuetos, 2013; Bravo-Valdivieso \& Escobar, 2014; Ijalba \& Obler, 2015; Lallier \& Carreiras, 2018).

However, even though significant differences were only found between AG (English) and JAP (Spanish), it was also noteworthy that the bilingual participants $\mathrm{CU}$ (ten) and RB (eight) got the lowest number of hits. This is significant for the study as both bilingual participants speak Spanish, which might mean that a double transfer effect was occurring while they were taking the test.

Similar results were obtained by Lallier and Carreiras (2018) with a larger sample, showing blended transfer between French (deep orthography) and Spanish (shallow orthography). Besides, the fact that our bilingual participants also produced the highest number of regularizations seems to further corroborate the presence of a double transfer effect. As mentioned above, Spanish speakers with motor-type aphasia tend to regularize the pronunciation of exception words.

There were also significant differences between the participants AG (English) and JAP (Spanish) for three-letter nonwords oral reading (PALPA 36/EPLA 34). It was noteworthy that all the Spanish participants except for JCM failed to read more nonwords than the English and bilingual speakers. Furthermore, only JCM was able to successfully read at least one nonword of any letter length in the Spanish group. The logical explanation is that JCM's severity rate is lower according to his profile in the BDAE test. He scored 5 in the severity rate, meaning that motor-type aphasia is barely affecting his performance.

On the other hand, in the English group, only AG failed to read four-letter nonwords, while in the bilingual group, RB failed to read five-letter nonwords. These results show that the Spanish participants used the damaged sublexical route more than the L1 English and English-Spanish bilingual speakers, thus reflecting the word-length effect addressed by Cuetos (2010).

The results of the morphological endings reading task (PALPA 34/EPLA 32) confirmed what Miozzo et al. (2010) had found in their study. They showed that their bilingual participants produced similar morphological errors, and 
little significant differences were found between our bilingual participants in morphological reading. It may be significant, however, that in the results of this pilot study both the bilingual and monolingual English speakers scored lower in the test of reading regularly inflected words than did the L1 Spanish participants. It is worth noting that these results regarding morphological and regularly inflected words reading were not found in other studies. Further research with a larger sample would be necessary to confirm these results in this pilot study,

Regarding the proportion of errors, the fact that the Spanish participants produced more neologisms than their English and bilingual counterparts seems to confirm their greater reliance on the phonological route when reading. These participants found it almost impossible to read nonwords due to their impaired access to the sublexical route, they would either produce a pseudoword or give a nonresponse. This would also explain why they had more difficulty reading low imageability words, exception words, and long nonwords. When these participants faced a word with low semantic weight or unknown to them, they relied on the sublexical route, as claimed by Cuetos $(2013,2010)$. This does not mean they cannot recognize the word they are trying to read aloud, but they simply cannot access their phonemic lexicon as their phonological route is damaged. The fact that the L1 Spanish participant JAP produced 22 semantic paralexias may suggest that the Spanish participant use the lexical route to access word meaning. On the other hand, the English and bilingual participants produced a higher number of lexicalizations (as reflected in Beeson et al., 2011). In the Spanish group, only GP produced more than one lexicalization. This seems to corroborate the L1 English and bilingual participants' higher dependence on the lexical route for reading. Therefore, we concluded that orthographic depth seems to play an important role in reading.

Other studies with monolingual participants speaking a transparent and/or an opaque language, including bilinguals of both languages, showed similar results to the ones displayed in this pilot study (Aziz et al., 2020; Dickens et al., 2019; Ijalba \& Obler, 2015; Kuzmina et al., 2019; Lallier \& Carreiras, 2018).

\section{Orthographic depth}

Our first research question asked if orthographic depth would affect word reading in individuals with motor-type aphasia. All the participants used both the lexical and sublexical routes when reading. However, in the case of L1 participants, depending on the language they spoke, the reliance on one route or the other changed. With bilingual participants, the logical procedure would be that they used the rules of their L1 rather than their L2's, considering they were L1-dominant speakers. However, they used strategies from both the L1 and L2, as they produced a high number of regularizations but also a lot of lexicalizations.

The L1 English participants showed a higher dependence on the lexical route when reading. Considering the opaque nature of the English language's 
orthography, with a high rate of words with no direct correspondence between spelling and sound, it seems logical that they produced more lexicalizations than the bilingual and L1 Spanish participants.

In contrast, the L1 Spanish participants depended more on the phonological route when reading. When their phonological route was damaged, the Spanish participants produced non-answers or more neologisms (invented words) than lexicalizations (nonwords turned into words) when reading nonwords. This does not mean they cannot recognize the word they are trying to read aloud. The fact that the L1 Spanish speakers, especially the patient JAP, produced semantic paralexias may show that the Spanish speakers with motor-type aphasia use the lexical route to access word meaning. Furthermore, even though their scores were lower than the L1 English and bilingual participants', they lexicalized nonwords as well. Therefore, greater reliance on the phonological route when reading does not nullify using the lexical route.

Finally, since they speak both a transparent and opaque language, the bilingual participants made more balanced use of both the lexical and phonological routes. As mentioned above, they produced more spelling-sound regularizations than the L1 English and L1 Spanish participants, as well as almost the same number of lexicalizations as the L1 English participants. They also made more neologisms than the L1 English participants, indicating that they tried to use the damaged phonological route while reading. Furthermore, the fact that they mixed strategies from L1 English and L1 Spanish speakers may indicate there is an interference between the opaque and transparent orthographies. Using both strategies may be useful when treating bilingual speakers with motor-type aphasia who speak both an opaque and transparent language. For example, knowing that the phonological route is damaged, their lexical reading can be reinforced more easily than if they speak only a transparent language. At the same time, their tendency to regularize exceptional words may also be used to rewrite them according to their real pronunciation. For example, if they have to read the exceptional word, for example a recipe, it could be written as 'recepy', so they can pronounce it / 'resipi/. It would also be convenient to add the picture of a recipe book so they can recognize the word via the semantic subroute in the lexical route, considering that the phonological route is damaged, but they still have access to the semantic system. In this case, the first step is to start treatment with the English language, as it is the one that uses the lexical route more than the sublexical/phonological route. The next step is to reorganize the damaged sublexical route using the Spanish language could follow.

\section{Linguistic variables}

The second research question concerned whether the same linguistic variables would affect Spanish, English, and bilingual speakers with motor-type aphasia.

The results showed that the L1 Spanish participants' reading skills were more 
affected by the word length effect, as they were unable to read long nonwords.

The L1 English participants' reading skills were also affected by the word length and spelling-sound regularization effects, but at a lower degree than the L1 Spanish and bilingual participants.

As for the bilingual participants, they were more affected by the spellingsound regularity effect, since they produced more spelling-sound regularizations of exception words than the L1 English participants. This suggests the presence of the double transfer effect; the bilingual participants were probably using the orthography-grapheme direct correspondence typical in transparent orthographies, so their production of regularizations was higher than in the case of the L1 English participants. This cannot be considered a signal of surface dyslexia because they produced lexicalizations, a type of error produced by individuals suffering from acquired phonological dyslexia.

\section{Conclusion}

The results obtained from this pilot study answered the two questions about the influence of linguistic effects varying according to orthographic depth and confirmed our hypothesis that different linguistic variables intervene in reading depending on the orthographic depth of the language(s) they speak. Even though the differences among the English, bilingual and Spanish participants were statistically significant, the obtained group differences seem important in the context of orthographic depth.

The findings of this pilot study could have implications for future research. It could help reinforce lexical reading in bilingual speakers with motor-type aphasia by rehabilitating the English language first using grapheme-phoneme mapping strategies through semantic support. Considering that bilingual speakers with motor-type aphasia have a wide range of possibilities to recover both languages, the route that is better preserved could be reinforced to eventually work on restructuring the route that is more damaged according to the reorganizing intervention program (Nickels, 2002). The advantage of speaking two languages with both an opaque and transparent orthographic system would ease the work of rehabilitation by using strategies from both English and Spanish.

However, even though the results corroborated the findings of other studies (Ijalba \& Obler, 2015; Lallier \& Carreiras, 2018), there are limitations that should also be considered in future research. The study should be replicated with a larger sample matched in education, age, and aphasia severity. With equal backgrounds, the similarity in the participants' performance would better reflect the real differences between L1 English, L1 Spanish, and bilingual speakers with motor-type aphasia. Potentially, the results would be more precise and statistically significant.

Despite these limitations, the results are well-grounded to further investigate 
these questions with a larger sample. It is also worth examining why the L1 Spanish participants, who scored lower in low imageability and functional word reading, did not obtain the same results in the morphological endings tests, considering that suffixes are abstract words as well. Additionally, it seems pertinent to verify if L1 English speakers obtain lower scores in reading regularly inflected words ending in -ed.

\section{Acknowledgments}

We would like to thank all the patients with motor-type aphasia who willingly participated in this pilot study, as well as the clinicians and speech therapists who referred them (the participants) to us.

\section{Conflict of Interest Disclosure}

The authors declare no conflicts of interest.

\section{Funding}

The authors have no sources of funding to declare.

\section{Research Ethics Statement}

No experiments were carried out on patients. The patients, all adults, took linguistic tests to assess their language production and comprehension, especially their reading abilities. Consent was given before starting the evaluation and their anonymity was guaranteed.

Since the participants' profiles are detailed, only the initials are provided so that their identities remain unknown to the readers. 


\section{References}

Ardila, A. (1998). Semantic paralexias in the Spanish language. Aphasiology, 12(10), 885-900. https://doi.org/10.1080/02687039808249457

Aziz, M. A. A., Razak, R. A., \& Garraffa, M. (2020). Targeting complex orthography in the treatment of a bilingual aphasia with acquired dysgraphia: The case of a malay/english speaker with conduction aphasia. Behavioral Sciences, 10(7), 109. https://doi.org/10.3390/bs10070109

Beeson, P. M., Rising, K., \& Rapcsak, S. Z. (2011). Reading and writing impairments. In L. L. LaPointe (Ed.), Aphasia and related neurogenic language disorders (pp. 121-139). Thieme.

Bravo-Valdivieso, L., \& Escobar, J. P. (2014). How transparent is Spanish orthography? / ¿Cuán transparente es nuestra ortografía castellana? Estudios de Psicología: Studies in Psychology, 35(3), 442-449 http://dx.doi.org/10.1 080/02109395.2014.965455

Coltheart, M., Rastle, K., Perry, C., Langdon, R., \& Ziegler, J. C. (2001). DRC: A dual-route cascaded model of visual word recognition and reading aloud. Psychological Review, 108(1), 204-256. https://doi.org/10.1037/0033295X.108.1.204

Coltheart, M. (1978). Lexical access in simple reading tasks. In G. Underwood (Ed.), Strategies of information processing (pp. 151-216). Academic Press

Coltheart, M. (2005). Modeling reading: The dual-route approach. In M. J. Snowling, C. Hulme, \& M. S. Seidenberg (Eds.), The science of reading: A handbook (pp. 6-23). Blackwell Publishing.

Cuetos, F., Valle, F., \& Suárez, M. P. (1996). A case of phonological dyslexia in Spanish. Cognitive Neuropsychology, 13(1), 1-24 https://doi. org/10.1080/026432996382042

Cuetos, F. (2006). Psicología de la lectura: Diagnóstico y tratamiento de los trastornos de lectura (6th ed.). Praxis

Cuetos, F. (2013). Psicología de la lectura (8th ed.). Wolters Kluwer.

Davies, R., \& Cuetos, F. (2010). Reading acquisition and dyslexia in Spanish. In N. Brunswick, S. McDougall, \& P. de Mornay Davies (Eds.), Reading and dyslexia in different orthographies (pp. 155-180). Psychology Press

Davies, R., Cuetos, F., \& Rodriguez-Ferreiro, J. (2010). Recovery in reading: A treatment study of acquired deep dyslexia in Spanish. Aphasiology, 24(10), 1115-1131 https://doi.org/10.1080/02687030902969792

Denise, H. W., Randi, C. M., \& Markus, F. D. (2002). A third route for reading? Implications from a case of phonological dyslexia. Neurocase, 8, 274-295 https://doi.org/10.1076/neur.8.3.274.16198

Dickens, J. V., Fama, M. E., DeMarco, A. T., Lacey, E. H., Friedman, R. B., \& Turkeltaub, P. E. (2019). Localization of phonological and semantic contributions to reading. The Journal of Neuroscience, 39(27), 5361-5368 https://doi.org/10.1523/JNEUROSCI.2707-18.2019 
Edmonds, L. A., \& Kiran, S. (2004). Confrontation naming and semantic relatedness judgements in Spanish/English bilinguals. Aphasiology, 18(5-7), 567-579 https://doi.org/10.1080/02687030444000057

Friedman, R. B. (1996). Recovery from deep alexia to phonological alexia: Points on a continuum. Brain and Language, 52(1), 114-128 https://doi. org/10.1006/brln.1996.0006

Goodglass, H., \& Kaplan, E. (2001). Boston Diagnostic Aphasia Examination (3rd ed.). Lippincott Williams y Wilkins

Hamers, J. F., \& Blanc, M. H. A. (1983). Bilinguality \& bilingualism. Cambridge University Press.

Hosogi, S. M. L., \& Pimenta Parente, M. A. M. (2012). Acquired dyslexia in three writing systems: Study of a Portuguese-Japanese bilingual aphasic patient. Behavioural Neurology, 25, 255-272 https://doi.org/10.3233/BEN2012-119001

Ijalba, E., \& Obler, L. K. (2015). First language grapheme-phoneme transparency effects in adult second-language learning. Reading in a Foreign Language, 27(1), 47-70. ISSN 1539-0578

Iribarren, C. (2007). Description and detection of acquired dyslexia and dysgraphia in Spanish. In Centeno, J. G., Anderson, R. T., \& Obler L. K. (Eds.), Communication disorders in spanish speakers: Theoretical, research and clinical aspects (pp. 231-241). Multilingual Matters

Kay, J., Lesser, R., \& Coltheart, M. (2012). Psycholinguistic Assessments of Language Processing in Aphasia (PALPA) (2nd ed.). Erlbaum

Kuzmina, E., Goral, Mira, N. M., \& Weekes, B. S. (2019). What influences language impairment in bilingual aphasia? A meta-analytic review. Frontiers in Psychology, 10(445) 1-22 https://doi.org/10.3389/fpsyg.2019.00445

Lallier, M., \& Carreiras, M.. (2018). Cross-linguistic transfer in bilinguals reading in two alphabetic orthographies: The grain size accommodation hypothesis. Psychonomic Bulletin \& Review, 25, 386-401. https://doi.org/10.3758/ s13423-017-1273-0

Lenneberg, E. H. (1967). Biological foundations of language. Wiley and Sons

Lesser, R., \& Milroy, L. (1993). Linguistics and aphasia: Psycholinguistic and pragmatic aspects of intervention. Longman

Lupker, S. J. (2005). Visual word recognition: Theories and findings. In Snowling, M. J., Hulme, C., \& Seidenberg, M. S. (Eds.), The science of reading: A handbook (pp. 39-60). Blackwell Publishing Ltd

Marshall, J. C., \& Newcombe, F. (1973). Patterns of paralexia: A psycholinguistic approach. Journal of Psycholinguistic Research, 2(3), 175-199 https://doi. org/10.1007/BF01067101

McCarthy, R. A., \& Warrington, E. K. (1990). Cognitive neuropsychology: A clinical introduction. Academic Press Inc.

Miozzo, M., Costa, A., Hernández, M., \& Rapp, B. (2010). Lexical processing in the bilingual brain: Evidence from grammatical/morphological deficits. 
Aphasiology, 10(2), 262-287 https://doi.org/10.1080/02687030902958381

Morton, J. (1979). Word recognition. In J. Morton \& J. Marshall (Eds.), Psycholinguistcs: Structures and Processes (pp. 107-156) Paul Eleck

Nickels, L. A. (2002). Therapy for naming disorders: Revisiting, revising and reviewing. Aphasiology, 16(10/11), 935-979 https://doi. org/10.1080/02687030244000563

Or-kan, S., Hazita, A., \& Su Mei H. (2020). A systematic review on bilingualism and language processing from 2015-2019. The Southeast Asian Journal of English Language Studies, 26(1), 18-31 http://dx.doi. org/10.17576/3L-2020-2601-02

Raven, J. C., Court, J.H., \& Raven, J. (1996). Raven matrices progresivas (2nd ed.). TEA ediciones, S.A

Rey, A., \& Osterrieth, P. A. (1994). Figura compleja de Rey (6th ed.). TEA ediciones,

Tainturier, M. J., Roberts, J., \& Leek, E. C. (2011). Do reading processes differ in transparent versus opaque orthographies? A study of acquired dyslexia in Welsh/English bilinguals. Cognitive Neuropsychology, 28(8), 546-563 https://doi.org/10.1080/02643294.2012.698986

Valian, V. (2015). Bilingualism and cognition. Bilingualism: Language and Cognition, 18(1), 3-24. https://doi.org/10.1017/S1366728914000522

Vellutino, F. R. (1982). Theoretical issues in the study of word recognition: The unit of perception controversy reexamined. In S. Rosenberg (Ed), Handbook of Applied Psycholinguistics (pp. 33-197). Erlbaum.

Vereda, C. (2018). El enfoque por tareas para mejorar las destrezas comunicativas en la enseñanza del inglés [Master's Dissertation, University of Malaga]. 